\title{
The 2018 ESC/ESH hypertension guidelines: Should nephrologists always stop at the lower boundary?
}

\author{
Gianpaolo Reboldi ${ }^{1}$ Giorgio Gentile ${ }^{1,2,3} \cdot$ Fabio Angeli $^{4} \cdot$ Paolo Verdecchia $^{5}$
}

Received: 16 August 2018 / Accepted: 17 August 2018 / Published online: 30 August 2018

(C) Italian Society of Nephrology 2018

\begin{abstract}
In patients with chronic kidney disease (CKD), hypertension is a major challenge because of its high prevalence, the consequent increase in cardiovascular morbidity and mortality, and the risk it confers specifically to the progression of kidney disease. Hence, establishing evidence-based blood pressure targets and treatment strategies is a clinical priority of paramount importance. Over the last few years, different guidelines have advocated different blood pressure treatment thresholds and goals in CKD patients, including a target $<140 / 90 \mathrm{mmHg}$ and a more intensive target-lower than $130 / 80 \mathrm{mmHg}$ - in the presence of albuminuria $\geq 300 \mathrm{mg} /$ daily. Aim of this article is to critically appraise the evidence base of the freshly released 2018 ESC/ESH European Guidelines, which recommend to lower systolic BP to a range 130 to $<140 \mathrm{mmHg}$ in patients with diabetic or non-diabetic CKD, also in view of the 2017 US guidelines, which favor a more intensive strategy with a $\mathrm{BP}$ target lower than $130 / 80 \mathrm{mmHg}$.
\end{abstract}

Keywords Hypertension $\cdot$ Chronic kidney disease $\cdot$ Guidelines $\cdot$ Blood pressure targets

\section{Introduction}

The optimal blood pressure (BP) target in hypertensive patients with chronic kidney disease (CKD) remains controversial. Some guidelines recommended a target $<140 / 90 \mathrm{mmHg}$ in these patients [1] and a more intensive target, $<130 / 80 \mathrm{mmHg}$, in the presence of albuminuria $\geq 300 \mathrm{mg}$ per day $[2,3]$. The scenario is complicated by

Electronic supplementary material The online version of this article (https://doi.org/10.1007/s40620-018-0526-y) contains supplementary material, which is available to authorized users.

Gianpaolo Reboldi

paolo.reboldi@unipg.it

1 Department of Medicine, Unversity of Perugia Medical School, Piazza Lucio Severi, 1, 06132 Perugia, Italy

2 Royal Cornwall Hospitals NHS Trust, Truro, UK

3 University of Exeter Medical School, Exeter, UK

4 Struttura Complessa di Cardiologia e Fisiopatologia Cardiovascolare, Ospedale S.Maria della Misericordia, Perugia, Italy

5 Fondazione Umbra Cuore e Ipertensione-ONLUS e Struttura Complessa di Cardiologia, Ospedale S. Maria della Misericordia, Perugia, Italy the concern that an intensive BP lowering strategy might be associated with a paradoxical rise in mortality and severe kidney failure ('J-curve' hypothesis), as suggested by studies in the general population [4] and in patients with CKD [5-8].

Recently, the Systolic Blood Pressure Intervention Trial (SPRINT) added an important piece of evidence in this area. In SPRINT, 28.3\% of participants had non-diabetic CKD at entry, defined by an estimated glomerular filtration rate (eGFR) between 20 and $59 \mathrm{ml} / \mathrm{min}$ per $1.73 \mathrm{~m}^{2}$ [9]. Patients were randomized to a more intensive $(<120 \mathrm{mmHg})$ or less intensive $(<140 \mathrm{mmHg})$ systolic BP target. In this study, the outcome benefits associated with the more intensive BP targets did not show any significant differences between the patients with and without CKD. In the subset of patients with CKD, all-cause mortality was reduced by $18 \%(p=0.04)$ in the more intensive compared with the less intensive treatment group [9]. Notably, several adverse events potentially associated with a more intensive BP lowering strategy (hypotension, syncope, bradycardia, injurious falls, hyponatremia, hypernatremia or orthostatic hypotension) did not differ between the more intensive and the less intensive treatment groups among the patients with CKD [9]. In contrast, hypokalemia, hyperkalemia and acute kidney failure were more frequent in the intensive treatment 
group [9]. Also on the basis of the SPRINT findings, the recent US Hypertension Guidelines approved by the American Heart Association, the American College of Cardiology and other 9 US Scientific Societies, recommended a BP target $<130 / 80 \mathrm{mmHg}$ (IB and IC for systolic and diastolic BP, respectively) in adult hypertensive patients with CKD [10].

The recently released 2018 European Society of Cardiology/European Society of Hypertension (ESC/ESH) Guidelines [11] addressed in detail the issue of hypertensive patients with concomitant CKD and recommended specific treatment strategies in terms of BP thresholds, BP targets, and antihypertensive drugs to prefer for clinical use.

\section{Take-home messages from European guidelines}

In brief, the European Guidelines state that 'in patients with diabetic or non-diabetic CKD, it is recommended that an office $\mathrm{BP}$ of $\geq 140 / 90 \mathrm{mmHg}$ be treated with lifestyle advice and BP lowering medication' (IA recommendation). Indeed, lifestyle changes are also advised in the subjects with high-normal BP (i.e., 130-139/85-89 mmHg) (IA recommendation). A few lines below, the European Guidelines add that 'in patients with diabetic or non-diabetic CKD it is recommended to lower systolic BP to a range 130 to $<140$ $\mathrm{mmHg}$ ' and that 'individualized treatment should be considered according to the tolerability and impact on renal function and electrolytes' (IIaC recommendation). The European Guidelines advise using renin-angiotensin system (RAS) blockers in patients with microalbuminuria or proteinuria (IA recommendation) and also recommend the combination between calcium channel blockers and RAS blockers as initial therapy in these patients (IA recommendation). Finally the Guidelines state that a combination between two different RAS blockers is strongly not recommended (IIIA recommendation) [11].

\section{The issue of therapeutic thresholds}

Where does the therapeutic threshold of $140 / 90 \mathrm{mmHg}$ in patients with diabetic and non-diabetic CKD spring from? Indeed, the recommendation of treating patients with office $\mathrm{BP} \geq 140 / 90 \mathrm{mmHg}$ with lifestyle measures and BP lowering drugs is based on three meta-analyses [12-14].

The first is a meta-analysis of 9 randomized trials which compared a more intensive $(<130 / 80 \mathrm{mmHg})$ versus a less intensive $(<140 / 90 \mathrm{mmHg})$ BP lowering strategy in non-diabetic adults with CKD. Average BP at entry was $<140 / 90 \mathrm{mmHg}$ in 4 of these studies, and 140/78 $\mathrm{mmHg}$ in another study. The results of meta-analysis were substantially negative. The annual rate of change in the glomerular filtration rate (GFR), the rate of doubling of serum creatinine, end-stage renal disease and all-cause mortality did not show any significant differences between the more intensive and the less intensive treatment groups. Only the subgroup of patients with proteinuria, and non-blacks patients, showed a trend toward a lesser kidney disease progression in the more intensive treatment group [13].

The second meta-analysis examined 11 randomized trials conducted in patients with CKD and comparing a more intensive versus a less intensive BP target [12]. The end-points were kidney failure (composite of doubling serum creatinine and $50 \%$ decline in GFR, or dialysis) or cardiovascular events (fatal or nonfatal myocardial infarction, fatal or nonfatal stroke or mortality). Again, BP at entry was $<140 / 90 \mathrm{mmHg}$ in 5 of these trials. Diabetic patients were excluded from 3 of these trials. Overall, the more intensive BP target was associated with a reduced risk of kidney failure only in the subset of patients with proteinuria (hazard ratio $0.73 ; 95 \% \mathrm{CI}$ $0.62-0.86$ ), not in those without proteinuria (hazard ratio 1.12; 95\% CI 0.67-1.87) [12]. There was no evidence of benefit from intensive BP lowering on the risk of major cardiovascular events or death [12].

The third meta-analysis was focused on all-cause mortality in 18 randomized trials that compared either a more intensive versus a less intensive BP target, or an active BP lowering treatment versus placebo or no treatment [14]. All these trials had been conducted in patients with eGFR $<60 \mathrm{ml} / \mathrm{min}$ per $1.73 \mathrm{~m}^{2}$. Systolic BP at entry was $<140 / 90 \mathrm{mmHg}$ in 6 of these trials, and only 12 trials included patients with diabetes. Overall, systolic BP fell by $16 \mathrm{mmHg}$ from baseline to follow-up in the more intensive arm and by $8 \mathrm{mmHg}$ in the less intensive arm [14]. All-cause mortality during follow-up was $14 \%$ lower in the more intensive than in the less intensive arm and results were consistent across several subgroups. In particular, the mortality benefit in the more intensive arm did not differ ( $\mathrm{p}$ for interaction: 0.56 ) according to baseline BP ( $<120 \mathrm{mmHg}$ versus $120-140 \mathrm{mmHg}$ vs $>140 \mathrm{mmHg}$ ) [14].

In order to investigate the conclusiveness of the available evidence and establish whether and when firm evidence of efficacy had been reached, we conducted a trial sequential analysis $[15,16]$ of the studies examined by Malhotra [14]. Notably, the mortality benefit remained consistently and steadily above the futility area, and it crossed the sequential monitoring boundary for efficacy before the required information size was reached, thus providing early and firm evidence of the beneficial effect of the more intensive BP strategy (Fig. 1).

\section{The issue of BP targets}

The European Guidelines base their recommendation of targeting systolic BP to below $140 \mathrm{mmHg}$, but not below $130 \mathrm{mmHg}$ (range of ' 130 to $<140 \mathrm{mmHg}$ '), in patients with 


\section{All Cause Mortality}

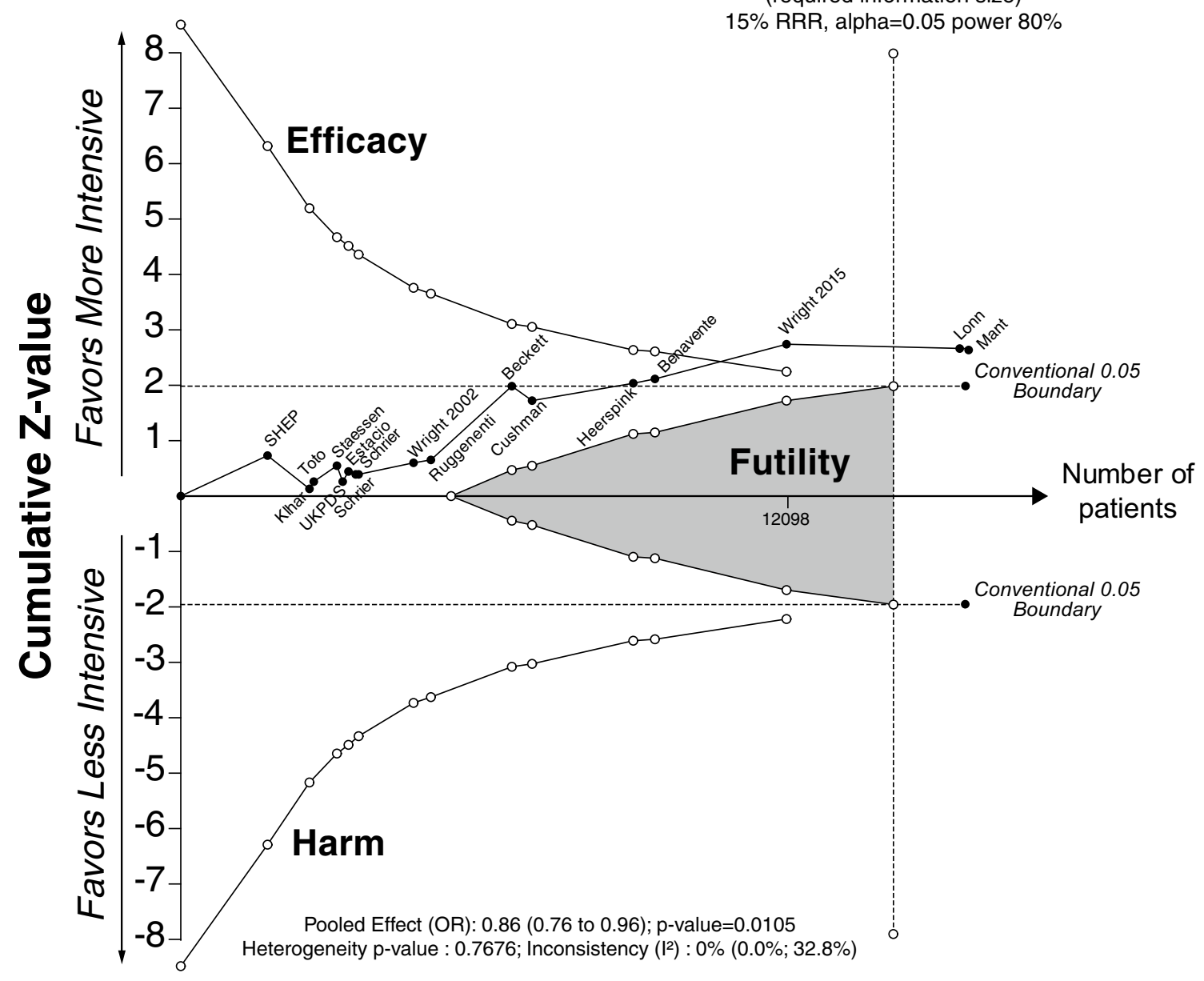

Diversity adjusted sample size $=14217$

(required information size)

$5 \%$ RRR, alpha $=0.05$ power $80 \%$
Fig. 1 Trial sequential analysis (TSA) of the effect of more intensive versus less intensive blood pressure reduction on morality in the studies examined by Malhotra et al. [14] The mortality benefit remained consistently and steadily above the futility area, and it crossed the sequential monitoring boundary for efficacy before the required information size was reached with no evidence for harmful effect. See Refs. $[15,16]$ for guidance on TSA and plot interpretation diabetic or non-diabetic CKD on two meta-analyses and a retrospective cohort study [11].

The first meta-analysis had been discussed above [13]. Notably, achieved systolic BP was lower than $130 \mathrm{mmHg}$ in some trials, ranging between 126 and $133 \mathrm{mmHg}$ in the more intensive arm, and between 134 and $141 \mathrm{mmHg}$ in the less intensive arm. The achieved differences in systolic BP varied between 4 and $13 \mathrm{mmHg}$. In the more intensive arm there was no evidence of increased risk of serious adverse events related to BP lowering (syncope, hypotension, acute kidney injury).

The second study is a patient-level meta-analysis of 11 randomized studies comparing regimens with and without angiotensin-converting-enzyme (ACE) inhibitors in patients with predominantly non-diabetic CKD [5]. However, type 1 diabetes was a pre-specified exclusion criterion, while type 2 diabetics $(\mathrm{N}=66)$ were subsequently excluded from the patient-level data analysis. Thus, the results of the meta-analysis are exclusively applicable to non-diabetic CKD. Both randomized groups were targeted to achieve BP levels $<140 / 90 \mathrm{mmHg}$. The primary outcome was kidney disease progression, defined as a composite of doubling of serum creatinine levels or initiation of dialysis. Systolic BP at entry was $>140 \mathrm{mmHg}$ in 10 of these trials. Mean systolic BP at follow-up was $<140 \mathrm{mmHg}$ in only 5 of these trials. In the total population, achieved systolic BP 110-129 $\mathrm{mmHg}$, and urine protein excretion $<2 \mathrm{~g} / \mathrm{dl}$, were associated with the lowest risk of kidney disease progression. There was a paradoxical rise in kidney disease progression ('J curve') for achieved systolic BP levels $<110 \mathrm{mmHg}$ (but not between 110 and $130 \mathrm{mmHg}$ ) in combination with urinary protein excretion $>1 \mathrm{~g} /$ day, although the authors conclude that 'reverse causation cannot be excluded with certainty' [5]. 
The third study considered by the Guidelines is a retrospective cohort study of an insurance database, conducted in 398,419 patients coded with diagnosis of hypertension [4]. Only $24 \%$ of these patients had concomitant CKD, defined by a GFR $<60 \mathrm{ml} / \mathrm{min}$ per $1.73 \mathrm{~m}^{2}$, and $30 \%$ had diabetes. The primary outcome was a composite of all-cause mortality or end-stage kidney disease, defined by dialysis or renal transplantation. The primary outcome showed a nadir at 130-139/60-79 $\mathrm{mmHg}$, with higher and lower values associated with worse outcome ('U curve') [4]. However, the primary outcome was almost entirely driven by allcause mortality. End-stage kidney disease showed a nadir at 110-140 $\mathrm{mmHg}$, with markedly increased risk for higher values and a slightly higher risk at levels $<110 \mathrm{mmHg}$. This finding is in close agreement with the previously discussed meta-analysis [5]. Reverse causality cannot be excluded with certainty to explain the higher risk of all-cause death in the subgroup with very low BP. Indeed, the prevalence of cerebrovascular disease, ischemic heart disease, diabetes and CKD were significantly higher in the group of patients with systolic $\mathrm{BP}<110 \mathrm{mmHg}$.

\section{Conclusions}

The IA recommendations by the European Guidelines that antihypertensive drug treatment should be initiated in patients with CKD only if office BP is $\geq 140 / 90 \mathrm{mmHg}$ despite lifestyle measures is not fully supported by evidence. Indeed, several 'strategy trials' comparing different BP targets or an active treatment versus placebo or no treatment have been conducted in patients with initial $\mathrm{BP}<140 / 90 \mathrm{mmHg}$. Hence, the conclusions of related metaanalyses cannot be attributed exclusively to patients with office $\mathrm{BP} \geq 140 / 90 \mathrm{mmHg}$.

Second, the recommendation of targeting systolic BP to below $140 \mathrm{mmHg}$, but not below $130 \mathrm{mmHg}$ (range of ' 130 to $<140 \mathrm{mmHg}$ ') in patients with diabetic or non-diabetic CKD is also not fully supported by evidence. Achieved BP during follow-up was $<130 \mathrm{mmHg}$ in several strategy trials, in the absence of serious adverse events potentially related to $\mathrm{BP}$ reduction. In the important meta-analysis by Malhotra et al. [14], the mortality benefit in the more intensive arm crossed the efficacy boundary early, and without evidence of harm or futility (Fig. 1). Furthermore, an important mortality benefit favoring the more intensive strategy (odds ratio 0.76 ; $95 \%$ confidence interval $0.62-0.93$ ) was noted in the studies which achieved the greatest difference across the groups ( $\geq 12 \mathrm{mmHg}$ ), although the interaction with BP strata bordered statistical significance $(\mathrm{p}=0.06)$.

On balance, evidence accrued so far does not support the recommendation by the European Guidelines to define 'safety boundaries' (i.e., $130 \mathrm{mmHg}$ ) in hypertensive patients with CKD, not to be exceeded regardless of the actual tolerability of treatment. Also, the European Guidelines are somewhat confusing and ambiguous, as they state that in patients with diabetic or non-diabetic CKD it is recommended to lower systolic BP to a range 130 to $<140 \mathrm{mmHg}$, but they also establish different targets for patients with diabetes [11], namely a recommended systolic BP target $120-130 \mathrm{mmHg}$ in patients aged $<65$ years and $130-139 \mathrm{mmHg}$ in those aged $\geq 65$ years. As patients with diabetic CKD implicitly fall into the specific subgroup of 'diabetes', this could lead to some unnecessary confusion on the appropriate systolic BP target in patients with CKD and diabetes. To further complicate the issue, the meta-analysis by Jafar et al. [5] - arguably the strongest piece of supporting evidence for diabetic and non-diabetic CKD patients referenced in the European Guidelines-has only included patients with non-diabetic CKD.

Ironically, the introduction of 'safety boundaries' recommended by the European guidelines in CKD patients seems to be mostly driven by the recent controversial findings in hypertensive patients without CKD. Indeed, a secondary analysis of the Action to Control Cardiovascular Risk in Diabetes (ACCORD) [17] and SPRINT trials showed that a more intensive BP lowering strategy increased the risk of incident $\mathrm{CKD}$, as defined by a $>30 \%$ reduction in eGFR to $<60 \mathrm{~mL} / \mathrm{min}$ per $1.73 \mathrm{~m}^{2}$, compared to standard BP lowering strategy $[18,19]$. However, as pointed out by several experts [20,21], the higher risk of incident CKD is likely to be overshadowed by the cardiovascular benefits as the systolic BP is reduced below $130 \mathrm{mmHg}$.

In a recent editorial [21], Mancia argues that the choice between cardiac protection and renal protection is illogical and unfeasible. Indeed, a unified intermediate BP target should be identified at which both cardiovascular and renal protection are maximized. Such unified target, the Holy Grail of Cardionephrology, might lie somewhere in the 120-130 mm Hg systolic range-i.e. certainly well below the 'range 130 to $<140 \mathrm{mmHg}$ ' advocated by the European Guidelines [11]. Sadly, the wisely worded message of this editorial [21] is not reflected by the freshly published European Guidelines.

In our current clinical practice, how should we manage hypertensive patients with CKD and treated BP below $130 \mathrm{mmHg}$ when the tolerability of treatment appears to be fully satisfactory or perfect? Following the Guidelines, it seems that we should consider withholding, partly or completely, drug treatment, in order to bring up systolic BP between 130 and $140 \mathrm{mmHg}$. In the current era of litigations, we wonder whether there may be the actual risk for doctors to be prosecuted, particularly in case of ensuing complications, for non-compliance with the recommendations of the European Guidelines, while in actual facts the patients were perfectly tolerating their 'excessively low' BP! 
In summary, we believe that there is robust evidence from individual trials and meta-analyses that BP should be treated at lower values, and lowered to lower values, than supposed so far. As a consequence, we also believe that the recent US Hypertension Guidelines [10] (BP target $<130 / 80$ in adult hypertensives with CKD) seem to adopt, in view of the evidence accrued so far, a more reasonable and balanced position compared to the European Guidelines. Having said that, we suggest that instead of fixing rigid BP targets or safety thresholds only barely supported by evidence, and until further trials comparing three rather than two systolic BP targets become available [22], we should be driven by two simple goals in our clinical practice. One, the conceptual acceptance of the notion that the lower the BP, the better, over a wide range of achieved BP; two, the pursuit of the best possible balance in each patient between the magnitude of BP reduction and the tolerability of treatment. Age, hypotension-related side effects, renal function and comorbidities appear to be main drivers in pursuing this balance not only in the patients with CKD, but probably in the totality of hypertensive patients.

Funding No fund was obtained for this article.

\section{Compliance with ethical standards}

Conflict of interest On behalf of all authors, the corresponding author states that there is no conflict of interest.

Ethical approval This article does not contain any studies with humans or animals performed by any of the authors.

Informed consent For this type of study formal consent is not required.

\section{References}

1. James PA, Oparil S, Carter BL, Cushman WC, Dennison-Himmelfarb C, Handler J et al (2014) 2014 evidence-based guideline for the management of high blood pressure in adults: report from the panel members appointed to the Eighth Joint National Committee (JNC 8). JAMA 311(5):507-520. https://doi.org/10.1001/ jama.2013.284427

2. Mancia G, Fagard R, Narkiewicz K, Redon J, Zanchetti A, Bohm $\mathrm{M}$ et al (2013) $2013 \mathrm{ESH} / \mathrm{ESC}$ guidelines for the management of arterial hypertension: the Task Force for the Management of Arterial Hypertension of the European Society of Hypertension (ESH) and of the European Society of Cardiology (ESC). Eur Heart J 34(28):2159-2219. https://doi.org/10.1093/eurheartj/eht151

3. Woo KT, Chan CM (2011) KDIGO clinical practice guidelines for bisphosphonate treatment in chronic kidney disease. Kidney Int 80(5):553-554. https://doi.org/10.1038/ki.2011.202 (author reply 554 )

4. Sim JJ, Shi J, Kovesdy CP, Kalantar-Zadeh K, Jacobsen SJ (2014) Impact of achieved blood pressures on mortality risk and endstage renal disease among a large, diverse hypertension population. J Am Coll Cardiol 64(6):588-597. https://doi.org/10.1016/j. jacc.2014.04.065
5. Jafar TH, Stark PC, Schmid CH, Landa M, Maschio G, de Jong PE et al (2003) Progression of chronic kidney disease: the role of blood pressure control, proteinuria, and angiotensin-converting enzyme inhibition: a patient-level meta-analysis. Ann Intern Med 139(4):244-252

6. Agarwal R (2009) Blood pressure components and the risk for end-stage renal disease and death in chronic kidney disease. Clin J Am Soc Nephrol 4(4):830-837. https://doi.org/10.2215/ CJN.06201208

7. Berl T, Hunsicker LG, Lewis JB, Pfeffer MA, Porush JG, Rouleau JL et al (2005) Impact of achieved blood pressure on cardiovascular outcomes in the Irbesartan Diabetic Nephropathy Trial. J Am Soc Nephrol 16(7):2170-2179. https://doi. org/10.1681/ASN.2004090763

8. Mahmoodi BK, Matsushita K, Woodward M, Blankestijn PJ, Cirillo M, Ohkubo T et al (2012) Associations of kidney disease measures with mortality and end-stage renal disease in individuals with and without hypertension: a meta-analysis. Lancet 380(9854):1649-1661. https://doi.org/10.1016/S0140 -6736(12)61272-0

9. Cheung AK, Rahman M, Reboussin DM, Craven TE, Greene T, Kimmel PL et al (2017) Effects of Intensive BP Control in CKD. J Am Soc Nephrol 28(9):2812-2823. https://doi.org/10.1681/ ASN.2017020148

10. Whelton PK, Carey RM, Aronow WS, Casey DE Jr, Collins KJ, Dennison Himmelfarb C et al (2018) 2017 ACC/AHA/AAPA/ $\mathrm{ABC} / \mathrm{ACPM} / \mathrm{AGS} / \mathrm{APhA} / \mathrm{ASH} / \mathrm{ASPC} / \mathrm{NMA} / \mathrm{PCNA}$ guideline for the prevention, detection, evaluation, and management of high blood pressure in adults: a report of the American College of Cardiology/American Heart Association Task Force on clinical practice guidelines. J Am Coll Cardiol 71 (19):e127-e248. https://doi.org/10.1016/j.jacc.2017.11.006

11. Williams B, Mancia G, Spiering W, Agabiti Rosei E, Azizi M, Burnier M et al (2018) 2018 ESC/ESH guidelines for the management of arterial hypertension. Eur Heart J. https://doi. org/10.1093/eurheartj/ehy339

12. Lv J, Ehteshami P, Sarnak MJ, Tighiouart H, Jun M, Ninomiya $\mathrm{T}$ et al (2013) Effects of intensive blood pressure lowering on the progression of chronic kidney disease: a systematic review and meta-analysis. CMAJ 185(11):949-957. https://doi. org/10.1503/cmaj.121468

13. Tsai WC, Wu HY, Peng YS, Yang JY, Chen HY, Chiu YL et al (2017) Association of intensive blood pressure control and kidney disease progression in nondiabetic patients with chronic kidney disease: a systematic review and meta-analysis. JAMA Intern Med 177(6):792-799. https://doi.org/10.1001/jamaintern med.2017.0197

14. Malhotra R, Nguyen HA, Benavente O, Mete M, Howard BV, Mant J et al (2017) Association between more intensive vs less intensive blood pressure lowering and risk of mortality in chronic kidney disease stages 3 to 5: a systematic review and meta-analysis. JAMA Intern Med 177(10):1498-1505. https:// doi.org/10.1001/jamainternmed.2017.4377

15. Wetterslev J, Thorlund K, Brok J, Gluud C (2008) Trial sequential analysis may establish when firm evidence is reached in cumulative meta-analysis. J Clin Epidemiol 61(1):64-75. https ://doi.org/10.1016/j.jclinepi.2007.03.013

16. Roshanov PS, Dennis BB, Pasic N, Garg AX, Walsh M (2017) When is a meta-analysis conclusive? A guide to trial sequential analysis with an example of remote ischemic preconditioning for renoprotection in patients undergoing cardiac surgery. Nephrol Dial Transplant 32(suppl_2):ii23-ii30. https://doi. org/10.1093/ndt/gfw219

17. Cushman WC, Evans GW, Byington RP, Goff DC Jr, Grimm RH Jr, Cutler JA et al (2010) Effects of intensive blood-pressure 
control in type 2 diabetes mellitus. N Engl J Med 362(17):15751585. https://doi.org/10.1056/NEJMoa1001286

18. Beddhu S, Greene T, Boucher R, Cushman WC, Wei G, Stoddard $\mathrm{G}$ et al (2018) Intensive systolic blood pressure control and incident chronic kidney disease in people with and without diabetes mellitus: secondary analyses of two randomised controlled trials. Lancet Diabetes Endocrinol 6(7):555-563. https://doi. org/10.1016/S2213-8587(18)30099-8

19. Sequeira-Lopez MLS, Gomez RA (2018) Preserving kidney health during intensive blood pressure control. Nat Rev Nephrol. https://doi.org/10.1038/s41581-018-0034-2

20. Neves JS, Leitao L, Magrico R, Dias CV, Vieira MB (2018) Risk-benefit profile of intensive blood pressure treatment. Lancet
Diabetes Endocrinol 6(8):601-602. https://doi.org/10.1016/S2213 -8587(18)30175-X

21. Mancia G (2018) Target blood pressure and kidney protection. Lancet Diabetes Endocrinol 6(7):521-523. https://doi. org/10.1016/S2213-8587(18)30134-7

22. Zanchetti A, Liu L, Mancia G, Parati G, Grassi G, StrambaBadiale $\mathrm{M}$ et al (2014) Blood pressure and low-density lipoprotein-cholesterol lowering for prevention of strokes and cognitive decline: a review of available trial evidence. J Hypertens 32(9):1741-1750. https://doi.org/10.1097/HJH.000000000000025 3 